\title{
Maintenance of Weight Loss in Adolescents: Current Status and Future Directions
}

\author{
Meghan L. Butryn, ${ }^{1}$ Thomas A. Wadden, ${ }^{2}$ Margaret R. Rukstalis, ${ }^{3}$ \\ Chanelle Bishop-Gilyard, ${ }^{2,4}$ Melissa S. Xanthopoulos, ${ }^{4}$ Delroy Louden, ${ }^{5}$ \\ and Robert I. Berkowitz ${ }^{2,4}$ \\ ${ }^{1}$ Department of Psychology, Drexel University, Philadelphia, PA 19104, USA \\ ${ }^{2}$ Department of Psychiatry, University of Pennsylvania, Philadelphia, PA 19104, USA \\ ${ }^{3}$ Center for Health Research, Geisinger Health Systems, Danville, PA 17822, USA \\ ${ }^{4}$ Department of Child and Adolescent Psychiatry, The Children's Hospital of Philadelphia, 3440 Market Street, Suite 410, \\ Philadelphia, PA 19104, USA \\ ${ }^{5}$ Anguilla Community College, George Hill British West Indies, PA 19104, USA
}

Correspondence should be addressed to Robert I. Berkowitz, berkowitz@email.chop.edu

Received 28 July 2010; Revised 20 October 2010; Accepted 14 November 2010

Academic Editor: Marion M. Hetherington

Copyright (C) 2010 Meghan L. Butryn et al. This is an open access article distributed under the Creative Commons Attribution License, which permits unrestricted use, distribution, and reproduction in any medium, provided the original work is properly cited.

There is a dearth of research on the long-term efficacy and safety of treatments for adolescent obesity. This narrative review examined several approaches to treatment, focusing on long-term effectiveness data in adolescents, as well as relevant findings from studies of adults. The available research suggests that lifestyle modification has promise in obese adolescents, although it is not clear that any particular dietary or physical activity approach is more effective than another. Meal replacements are quite effective in adults and deserve further research in adolescents. Extending the length of treatment to teach weight loss maintenance skills is likely to improve long-term outcomes in adolescents, and delivering treatment via the Internet or telephone is a novel way of doing so. Treatment that combines lifestyle modification with the medication orlistat generally appears to be safe but only marginally superior to lifestyle modification alone. More research is needed on the management of adolescent obesity, which has been overlooked when compared with research on the treatment of obesity in children and adults.

\section{Introduction}

The rate of obesity has tripled in adolescents in the United States over the last 20 years [1]. (Adolescents whose BMIs for age and gender $\geq 85$ th percentile but $<95$ th percentile are categorized as "overweight," and those who are $\geq 95$ th percentile are considered "obese" [2-4].) Innovative prevention programs, as well as changes in policies concerning food and physical activity, are needed to reverse this alarming increase in obesity [2,5]. At the same time, effective treatment options are needed for adolescents who are already obese. Treatment programs should help obese adolescents achieve and maintain clinically significant weight loss that will reduce their risk for cardiovascular disease and type 2 diabetes mellitus and improve their quality of life.
Research on the treatment of adolescent obesity has been largely overlooked, particularly compared with that conducted on children and adults. Adolescence is a period with special developmental considerations, and it is not clear that programs developed for children or adults are effective in adolescents. For example, parents typically have less influence on an adolescent's eating and physical activity habits than on a child's behavior. Motivation to seek treatment may be different for adolescents than adults because the health consequences of obesity are less salient to youth. However, body dissatisfaction and the impact of weight on self-esteem may be especially pronounced in adolescents. Approximately two dozen randomized controlled trials of weight loss interventions have been conducted in adolescents since 1998, and about half of these studied medications 
(i.e., orlistat, sibutramine, metformin) [6]. According to a recently updated Cochrane Review and several other summaries and meta-analyses [6-10], most of these interventions produced only modest reductions in BMI at 6 and 12 months, which yielded only small to moderate effect sizes (as compared with control interventions).

There is a particular dearth of research on the longterm efficacy and safety of treatments for adolescent obesity $[6,9]$. Reviews of the literature, as well as practice guidelines, have concluded that more research is needed, with specific attention to long-term outcomes $[6,7,9,11,12]$. Longterm is defined here as at least 8 months of treatment and followup, the latter which may include only assessment or assessment plus continued weight loss maintenance therapy. The 8-month period is shorter than the 1-year standard for long-term treatment in adults, and reflects that adolescents are typically treated for shorter periods than adults.

As with adults, the Achilles heel of weight management in adolescents is likely to be weight loss maintenance, but very few studies have tested the effectiveness of treatments that are specifically aimed at addressing the challenge of weight loss maintenance. On average, adolescents who present for treatment have a weight of approximately $100 \mathrm{~kg}$ (and BMI of 35 to $40 \mathrm{~kg} / \mathrm{m}^{2}$ ) [13]. Thus, it is appropriate for their weight management goal to be achieving a significant weight loss and avoiding weight regain, in contrast to young children, whose baseline weights are lower and for whom a reasonable long-term goal may be to avoid some or all of the weight gain that would normally continue to occur as the child grows.

\section{The Problem of Adolescent Obesity}

Adolescent obesity is known to increase the rate of adverse health events. Approximately $80 \%$ of obese adolescents will become obese adults and, as a result, experience increased risks of hyperlipidemia, hypertension, type 2 diabetes mellitus, gallbladder disease, sleep disorders, and some forms of cancer (e.g., breast, uterine, prostate, and colon) [14-16]. Longitudinal studies have clearly demonstrated the adverse health effects in adulthood of having been obese as an adolescent $[17,18]$. Recent investigations also have shown that obese teens may not be spared from health complications until they reach adulthood. At present, diabetes is the third most prevalent severe chronic disease of childhood in the U.S., with the highest incidence occurring in youth from racial and ethnic minority backgrounds [19-21]. Nearly half of newly diagnosed cases of diabetes are associated with obesity [22]. Individuals in whom diabetes is diagnosed before the age of 20 years have a life expectancy 15-27 years shorter than people without diabetes [21]. In addition, metabolic syndrome is increasing rapidly in adolescents. In some samples, as many as $18 \%$ of adolescents with obesity met criteria for metabolic syndrome [23].

2.1. Quality of Life. The medical complications of adolescent obesity are compounded by adverse psychosocial and economic effects, which may be the most widespread consequences of the disorder [24]. A telling study by Gortmaker et al. [25] revealed that, by their early 20s, women who had been obese in adolescence were poorer, less educated, and less likely to be married than were women who had been nonobese as adolescents. Findings from the Nurses' Health Study II [26] revealed that a BMI $\geq 25 \mathrm{~kg} / \mathrm{m}^{2}$ at age 18 years was associated with a hazard ratio of 2.3 (CI, 1.20 to 4.42) for death due to suicide, compared with a BMI of 18.5 to $21.9 \mathrm{~kg} / \mathrm{m}^{2}$. Furthermore, health-related quality of life-including physical health, emotional, social, and school functioning - was reported to be significantly lower in adolescents with obesity compared with average weight peers and was similar to adolescents diagnosed with cancer [27].

2.2. Benefits of Weight Loss. Weight loss is associated with reduction in risk for diabetes and cardiovascular disease, as well as marked improvements in blood pressure, triglycerides, and HDL cholesterol in overweight and obese adults [28-32]. Weight loss similarly ameliorates CVD risk factors in obese adolescents. Improvements are not as dramatic as those observed in adults because obese youth typically have not developed clinically significant disease. Berkowitz et al. [13], for example, found that systolic blood pressure fell from 114 to $110 \mathrm{~mm} \mathrm{Hg}$ in adolescents who achieved a $4 \%$ reduction in BMI with a lifestyle modification program [13]. Participants also experienced a $14.8 \%$ reduction in insulin resistance and improvements in HDL cholesterol and triglycerides. In extremely obese adolescents with type 2 diabetes, Roux-en-Y gastric bypass was associated with the remission of this condition and with marked improvements in quality of life [33]. In summary, sustained weight loss likely confers important medical and psychosocial benefits for obese adolescents.

\section{Aims and Methods of Review}

In this narrative review, we examine the long-term (i.e., $>8$ months) effectiveness of several approaches for the treatment of adolescent obesity, including lifestyle modification, dietary and physical activity interventions, use of Internet and telephone, and medication. Studies were identified by (1) examining the reference list of recent systematic reviews of childhood or adolescent obesity treatment (none of which focused specifically on long-term outcomes), (2) examining the reference lists of the studies identified for inclusion, and (3) completing the literature search for articles published from January 2007 to May 2010 to ensure inclusion of the most recent studies. (Searches were completed with various combinations of the following terms: adolescent, adolescence, teenage, obesity, obese, overweight, weight loss, weight maintenance, intervention, treatment, program, and clinical trial.) Studies were included only if they met all of the following criteria: participants were overweight or obese at the time of enrollment; participants were in the adolescent age range; a no-treatment followup assessment was included or, if only posttreatment data were collected, treatment (including weight loss maintenance) was provided for $>8$ months; change in weight or body fat was measured as a primary outcome; participants were randomly assigned 
to treatment condition; and treatment provided lifestyle modification, dietary or exercise counseling, or medication for the purposes of weight control. When results from a study were reported in more than one publication, only the primary outcomes paper was included. Table 1 provides information on the characteristics of included studies (i.e., sample size, method of data analysis, attrition, length of treatment, and length of followup). After reviewing the included studies, we also summarize findings from studies of adults, evaluate the promise of each approach for adolescent weight loss maintenance, and offer recommendations for future research and practice.

\section{Lifestyle Modification}

4.1. Components of Lifestyle Modification. Lifestyle modification for weight control is based on social cognitive theory $[49,50]$. It provides adolescents with a set of principles and techniques to modify their food intake, physical activity, and cognitions to induce the modest negative energy balance (e.g., $500 \mathrm{kcal} / \mathrm{d}$ ) required for weight loss. Adolescents are instructed to keep daily records of their food intake, and they typically are encouraged to consume a low-fat diet. Activity interventions may include programmed exercise (e.g., planned aerobic workouts), lifestyle activity (e.g., increasing steps with the use of a pedometer), and efforts to decrease sedentary behaviors (e.g., reducing TV viewing) [51-53]. Cognitive therapy teaches adolescents to identify negative, self-defeating thoughts and to replace them with more accurate, positive statements $[49,50]$. Treatment also relies heavily on stimulus control techniques, designed to limit eating to specific times and places and to avoid other activities while eating. An initial course of treatment typically lasts 4 to 6 months and is delivered to groups of 8 to 15 adolescents by health professionals, including psychologists, dietitians, exercise specialists, and nurses. Comprehensive programs also typically instruct parents/caregivers in methods to support their adolescents' weight loss efforts $[49,50]$. A comprehensive lifestyle modification program typically induces a loss of 2 to $4 \mathrm{~kg}$ in 6 months, equal to about a 2 to $4 \%$ reduction in initial BMI [6-10]. Differences between intervention and control groups are typically due not only to weight loss, but also to the prevention of weight gain that would otherwise occur [10]. While these weight losses are beneficial, most adolescents nevertheless remain very obese following therapy, having begun treatment with an initial weight of approximately $100 \mathrm{~kg}$ (and BMI of 35 to $40 \mathrm{~kg} / \mathrm{m}^{2}$ ) [13].

4.2. Long-Term Effectiveness of Lifestyle Modification in Adolescents. Few randomized controlled trials (RCTs) have tested the effectiveness of standard lifestyle modification in an adolescent sample with (1) a treatment period of longer than 8 months or (2) a posttreatment followup period. (Lifestyle modification programs that prescribe a special diet or physical activity regimen or delivery of treatment via the Internet or telephone are examined in subsequent sections of this review.) With one exception, which is noted, all of these studies delivered lifestyle modification in group format. One early RCT yielded promising longterm outcomes [34]. Participants who completed the lifestyle modification program had significantly better improvements in relative weight (i.e., actual weight divided by expected weight for age, sex, and height) at 1-year followup than control group participants. At 1-year followup, the treatment group maintained a weight loss of $3.9 \mathrm{~kg}$, while weight increased $1.3 \mathrm{~kg}$ in the control group.

Four RCTs tested the effectiveness of adolescent lifestyle modification combined with parental involvement. One of these studies [35] evaluated the effectiveness of a 2-year, family-based behavioral treatment program for obese adolescents in China. Monthly home visits were conducted for all treatment sessions, rather than the traditional clinic-based group format. BMI decreased significantly in adolescents in the treatment group, for a total reduction of $9.8 \%$ at 2 years, whereas no significant reduction in BMI was observed in the control group. This study demonstrated that homebased, family-oriented treatment was more effective than no treatment. Another RCT [36] compared the effectiveness of lifestyle modification when adolescents were treated alone versus when their parents also received treatment in a separate group. At the end of treatment, the reduction in percentage overweight was significantly larger in the condition in which parents were involved in treatment than when adolescents were treated alone. However, at the 9month followup, there were no differences between groups, at which time both groups maintained an average reduction in percentage overweight of approximately $8 \%$. Finally, two RCTs examined three different approaches to lifestyle modification; each of which provided 16 weeks of treatment: (1) adolescent treated with no parent participation; (2) mother and adolescent treated in the same sessions; and (3) mother and adolescent treated in separate but concurrent sessions. In the first of those two studies [37], the largest initial weight losses were observed in the condition in which mothers and adolescents were treated in separate but concurrent sessions. Differences between the groups grew in magnitude and were significant at 16 months: adolescents in the separate but concurrent treatment condition maintained a weight loss of $7.7 \mathrm{~kg}$, whereas those in the other conditions experienced a weight gain of approximately $3 \mathrm{~kg}$ above baseline weight. In contrast, the second study using this design [38] found that weight change did not differ significantly between conditions at 6-months followup, at which time approximately half of participants remained below baseline BMI. Only $11 \%$ of participants maintained a reduction in BMI of $5 \%$ or more, and $21 \%$ showed an increase of $5 \%$ or more. The lack of benefit of parent participation observed in this study is consistent with the results of a meta-analysis that found that parent participation in treatment had a larger benefit for children under age 8 years than for older children [9]. The results of this study are also consistent with many studies of lifestyle modification in adults, which typically found that maintenance of treatment effects was poor $[54,55]$.

Several RCTs have tested innovative methods of delivery of lifestyle modification to adolescents. Coates et al. [39] conducted an RCT with a $2 \times 2$ factorial design to compare 
TABle 1: Characteristics of Adolescent Clinical Trials.

\begin{tabular}{|c|c|c|c|c|c|}
\hline Author & $\begin{array}{l}\text { Sample } \\
\text { size }\end{array}$ & Method(s) of data analysis & $\begin{array}{l}\text { Attrition at end of } \\
\text { study }\end{array}$ & $\begin{array}{l}\text { Length of } \\
\text { treatment }\end{array}$ & $\begin{array}{l}\text { Length of followup } \\
\text { (i.e., months after } \\
\text { treatment } \\
\text { completion) }\end{array}$ \\
\hline Mellin et al. [34] & 66 & $\begin{array}{l}\text { Not clear; presumably } \\
\text { completers only }\end{array}$ & $16 \%$ & 3 months & 12 months \\
\hline Jiang et al. [35] & 75 & Completers only & $8 \%$ & 24 months & None \\
\hline Coates et al. [36] & 31 & $\begin{array}{l}\text { Not clear; presumably } \\
\text { completers only }\end{array}$ & None reported & 20 weeks & 9 months \\
\hline Brownell et al. [37] & 42 & $\begin{array}{l}\text { Not clear; presumably } \\
\text { completers only }\end{array}$ & $14 \%$ & $\begin{array}{l}16 \text { months } \\
\text { (sessions were held } \\
\text { every } 2 \text { months } \\
\text { after the initial } 16 \\
\text { weekly sessions) }\end{array}$ & None \\
\hline Wadden et al. [38] & 47 & Completers only & $34 \%$ & 4 months & 6 months \\
\hline Coates et al. [39] & 42 & $\begin{array}{l}\text { ITT, in which return to } \\
\text { baseline weight was } \\
\text { assumed for participants } \\
\text { who did not provide data }\end{array}$ & $14 \%$ & 20 weeks & 6 months \\
\hline Resnicow et al [40] & 147 & $\begin{array}{l}\text { (1) ITT (unclear how } \\
\text { missing data were } \\
\text { handled), and (2) } \\
\text { inclusion of only those } \\
\text { participants who } \\
\text { completed at least } 75 \% \text { of } \\
\text { treatment sessions }\end{array}$ & $27 \%$ & 6 months & 6 months \\
\hline Ebbeling et al. [41] & 16 & $\begin{array}{l}\text { ITT, in which return to } \\
\text { baseline weight was } \\
\text { assumed for participants } \\
\text { who did not provide data } \\
\text { (completers analysis also } \\
\text { reported in paper, with } \\
\text { same result) }\end{array}$ & $13 \%$ & 6 months & 6 months \\
\hline Gutin et al. [42] & 80 & $\begin{array}{l}\text { (1) Completers only and } \\
\text { (2) inclusion of only those } \\
\text { participants who attended } \\
\text { at least } 40 \% \text { of treatment } \\
\text { sessions and at least two } \\
\text { sessions per week of } \\
\text { physical activity }\end{array}$ & $29 \%$ & 8 months & None \\
\hline Jelalian et al. [43] & 76 & $\begin{array}{l}\text { (1) Completers only and } \\
\text { (2) ITT, in which return } \\
\text { to baseline weight was } \\
\text { assumed for participants } \\
\text { who did not provide data }\end{array}$ & $26 \%$ & 4 months & 6 months \\
\hline $\begin{array}{l}\text { Williamson et al. } \\
{[44]}\end{array}$ & 57 & $\begin{array}{l}\text { ITT with LOCF (authors } \\
\text { also noted that same } \\
\text { results were found with } \\
\text { completers analyses) }\end{array}$ & $30 \%$ & 24 months & None \\
\hline Doyle et al. [45] & 80 & $\begin{array}{l}\text { (1) Completers only and } \\
\text { (2) ITT, in which return } \\
\text { to baseline weight was } \\
\text { assumed for participants } \\
\text { who did not provide data }\end{array}$ & $17 \%$ & 4 months & 4 months \\
\hline Jones et al. [46] & 105 & $\begin{array}{l}\text { (1) Completers only and } \\
\text { (2) ITT, in which return } \\
\text { to baseline weight was } \\
\text { assumed for participants } \\
\text { who did not provide data }\end{array}$ & $17 \%$ & 4 months & 5 months \\
\hline
\end{tabular}


TABLE 1: Continued.

\begin{tabular}{|c|c|c|c|c|c|}
\hline Author & $\begin{array}{l}\text { Sample } \\
\text { size }\end{array}$ & Method(s) of data analysis & $\begin{array}{c}\text { Attrition at end of } \\
\text { study }\end{array}$ & $\begin{array}{l}\text { Length of } \\
\text { treatment }\end{array}$ & $\begin{array}{l}\text { Length of followup } \\
\text { (i.e., months after } \\
\text { treatment } \\
\text { completion) }\end{array}$ \\
\hline $\begin{array}{l}\text { Chanoine et al. } \\
{[47]}\end{array}$ & 539 & $\begin{array}{l}\text { Modified ITT: inclusion } \\
\text { of all randomized } \\
\text { participants who } \\
\text { completed at least one } \\
\text { postbaseline visit, with } \\
\text { LOCF for subsequent } \\
\text { missing data }\end{array}$ & $35 \%$ & 12 months & None \\
\hline Ozkan et al. [48] & 42 & Completers only & $17 \%$ & $\begin{array}{l}\text { Mean } 11.7 \pm 3.7 \\
\text { months }\end{array}$ & None \\
\hline
\end{tabular}

Note: ITT : Intention-to-treat analysis; $\mathrm{LOCF}=$ last observation carried forward.

four treatment conditions, all of which included behavioral treatment. The factors were monetary reinforcers (for weight loss versus self-reported calorie intake) and frequency of therapeutic contact (five times versus one time per week). The treatment group that received monetary rewards for weight loss and came to the clinic five times per week was the only group to demonstrate a significant reduction in percent overweight from pre- to posttreatment, and from pretreatment to 6-month followup. Novel settings for delivery of weight loss interventions also have been examined. Resnicow et al. [40] evaluated a church-based, culturally-tailored lifestyle modification program for overweight, African American, adolescent females. Churches were randomized to either a high-intensity (20 to 26 sessions) or moderateintensity (six sessions) intervention. In addition to standard behavioral components, participants also engaged in physical activity and prepared and tasted healthy foods during each session. Neither intervention induced significant weight loss. At posttreatment and 6-month followup, BMI did not differ significantly between groups. Post-hoc analyses, however, found that participants who attended at least $75 \%$ of the sessions $(47 \%$ of participants in that condition met this criterion) showed favorable changes in BMI and that these changes were sustained or enhanced at followup.

4.3. Conclusions. Long-term effectiveness data are available from a small number of RCTs of lifestyle modification in adolescents, and the evidence from these studies was mixed. Participants in some of these studies were able to maintain a meaningful weight loss, whereas other longterm results were disappointing. There is not yet a large enough body of evidence to recommend targeted changes to lifestyle modification. One of the most promising results was produced by a home-based treatment program that involved the family and provided intervention over a period of 2 years; this study was conducted in China, and replication of these results in Western cultures is necessary.

Providing continued treatment during weight loss maintenance has shown promise in adult populations [56]. Recently published data from the Look AHEAD study found that, using intention-to-treat (ITT) analyses, after 4 years of continued treatment participants maintained a weight loss of $4.7 \%$ of initial weight [57]. Maintenance sessions may provide participants with the support and motivation they need to continue to practice weight control behaviors, such as keeping food records and exercising regularly [58]. However, other research has failed to find a benefit of continued contact [59], and attendance often decreases when treatment is extended $[60,61]$. Continued contact also can be expensive, so if effectiveness is more consistently demonstrated, ways to deliver it with reduced cost will need to be investigated.

Particular developmental issues need to be considered in the long-term treatment of adolescents, including the possibility of patients leaving the geographic area of the clinic after high school (e.g., to attend college) and the challenges of maintaining a constant meeting time for group treatment when schedules for extracurricular activities or part-time employment change. Other important developmental considerations need to be addressed in future research, including the appropriateness of single-sex versus coeducational group treatment and the best way to involve parents or other family members in treatment. Although the data on the benefits of parental involvement are mixed, a developmental perspective would suggest that involving parents in adolescent lifestyle modification programs is likely to be valuable because of the powerful influence parents have on the adolescent's weight control behaviors (e.g., by influencing the extent to which the home environment supports healthy eating and physical activity). Future research should conduct posttreatment followup of adolescents in lifestyle modification programs and also continue to study the extent to which parental involvement and extended treatment can improve outcomes. Several of the studies reviewed here conducted statistical analyses with completers only; future research should use ITT analyses with appropriate handling of missing data.

\section{Dietary Interventions}

5.1. Effect of Dietary Interventions. Standard lifestyle modification programs prescribe a diet in which calories and fat are limited (i.e., to create an energy deficit of $500 \mathrm{kcal} / \mathrm{d}$, with fewer than $30 \%$ of calories from fat in the diet). Additional dietary interventions have been developed to 
enhance adherence to these goals or to alter the composition of the diet to facilitate negative energy balance or weight loss maintenance.

5.2. Long-Term Effectiveness of Dietary Interventions in Adolescents. Pediatric trials that have modified the macronutrient composition of the diet have not reliably produced larger weight losses in the short-term than the standard lifestyle modification diet [6-9]. Long-term data on the effectiveness of dietary interventions in outpatient treatment of adolescents are available from only one RCT. In this study, participants followed either an ad libitum, reduced-glycemic load diet or an energy-restricted, reduced-fat diet [41]. Dietary intervention was combined with behavioral therapy and provided in 12 sessions over the weight loss period. Participants in the glycemic diet condition experienced no significant weight regain during the 6-month followup period. From baseline to followup, average changes in BMI differed significantly between groups. In ITT analyses, BMI decreased $1.2 \mathrm{~kg} / \mathrm{m}^{2}$ in the glycemic diet condition and increased $0.6 \mathrm{~kg} / \mathrm{m}^{2}$ in the reduced-fat condition. Replication of this finding is necessary, particularly because this study had a small sample size.

The first RCT examining the use of meal replacements in obese adolescents is currently being conducted by Berkowitz and colleagues. This study will provide important information about the effectiveness of such a diet in this population. An uncontrolled pilot study of this approach in adolescents found that meal replacements successfully induced weight loss and were acceptable to participants [62]. Meal replacements, which include liquid shakes, meal bars, and frozen food entrees, provide dieters a fixed amount of food, with a known calorie content. Using the principle of stimulus narrowing, they often reduce dieters' contact with problem foods and the difficulties they may experience in deciding what to eat (which may lead to overeating) [54]. Meal replacements also are relatively inexpensive compared to conventional foods and require little preparation. They may be especially appropriate for adolescents, who often have not yet developed skills for preparing healthy foods, and who may not have a home or school environment in which healthy meals are available.

5.3. Conclusions. There are not yet sufficient data from studies of dietary approach to weight loss maintenance in adolescents. Investigations of adults indicate that calorie intake, rather than macronutrient composition of the diet, is the most important determinant of weight loss maintenance. Several RCTs conducted with adults have compared weight loss maintenance using low-fat, ad libitum calorie diets versus restricted-calorie diets $[27,63,64]$, or low-carbohydrate diets versus low-fat diets [65-67]. No diet has emerged as consistently more effective than another in the long-term. In the largest, long-term RCT [68] conducted to date, four diets were compared. At 2 years, weight loss was similar in groups that were assigned to a diet with low- or highprotein, low- or high-fat, and low- or high-carbohydrates. The choice of a particular dietary approach depends, in large measure, on personal preference. Treatment providers also should consider whether a particular diet (e.g., one that is low in carbohydrate) is most likely to control comorbid conditions in a patient (type 2 diabetes). The use of portioncontrolled servings and meal replacements currently has the strongest evidence of long-term efficacy in adults [69-71]. These products eliminate the need to weigh and measure foods, save time planning and preparing meals, and reduce contact with problem foods [72]. To the extent that they reduce dietary variety, they also may better satisfy appetite [73-75]. Increasing dietary structure in the form of detailed meal plans also improves weight loss maintenance [76].

Future research with adolescents must be conducted with long-term followup to evaluate weight loss maintenance and determine the safety of each diet with respect to the particular developmental needs of adolescents. For instance, diets must promote adequate calcium intake, which is vital for bone development. Although behavioral treatment programs are unlikely to increase risk for eating disorders [77], adolescents are at higher risk for eating disorders than adults, so research must continue to evaluate the consequences of particular diets for binge eating, purging, fasting, and other disordered eating behaviors. In addition, the support provided by parents (e.g., foods available at home, foods prepared for family meals) and the food environment in a patient's school and community are likely to influence the extent to which an adolescent successfully makes changes in their diet.

\section{Physical Activity Interventions}

6.1. Nature of Physical Activity Interventions. Treatment guidelines indicate that obese adolescents should be physically active for a minimum of one hour per day and reduce television viewing and other screen time to no more than one hour per day [7]. Lifestyle modification for adolescents typically includes programmed exercise, lifestyle activity, and efforts to decrease sedentary behaviors. As with dietary interventions, some studies have tested whether modifying the standard approach to physical activity promotion can improve weight loss maintenance.

6.2. Long-Term Effectiveness of Physical Activity Interventions in Adolescents. Pediatric trials that have assessed different types of physical activity components have not reliably produced larger weight losses, although moderate benefits for adiposity have been documented [6-9]. Two RCTs examined physical activity interventions in obese adolescents with either (1) a treatment period of longer than 6 months or (2) a posttreatment followup. Gutin et al. [42] compared three interventions during an 8-month intervention period: (1) standard lifestyle modification, (2) lifestyle modification plus moderate-intensity supervised physical activity, or (3) lifestyle modification plus high-intensity supervised physical activity. The physical activity interventions included several features that were expected to be appealing to adolescents, such as prizes for hitting target heart rates and activities that they might especially enjoy (e.g., kickball). Change 
in body fat percentage did not differ between groups in ITT analyses. However, when only those participants who attended at least $40 \%$ of treatment sessions and at least two sessions per week of physical activity were included in the analysis and participants in the two physical activity conditions were combined $50 \%$ of participants in those conditions met this criterion), change in percentage body fat was significantly different between groups. It decreased $3.6 \%$ in the lifestyle modification plus supervised physical activity group and increased $0.2 \%$ in the standard lifestyle modification group. Jelalian et al. [43] conducted a study in which adolescents participated in a lifestyle modification program in conjunction with either peerenhanced adventure therapy (similar to Outward Bound) or aerobic exercise. The peer-enhanced adventure therapy was expected to be especially appropriate for adolescents, because it was designed to increase self-confidence, selfefficacy, and mutual support among peers (who are influential models of behavior during this developmental period). Analysis of treatment completers at 6-months followup indicated that the percentage of participants maintaining a $4.5 \mathrm{~kg}$ or higher weight loss was significantly higher in the adventure therapy condition than the aerobic condition (35\% versus $12 \%)$. However, ITT analyses found no significant difference between groups in weight change over time.

6.3. Conclusions. Few RCTs of obese adolescents have examined which approaches to physical activity produce the best weight loss maintenance, and no study has experimentally examined the amount of physical activity that is necessary for weight loss maintenance. Because physical activity unquestionably confers health benefits, it should be included in treatment programs for adolescent obesity [78]. In the adult literature, there is strong correlational evidence that high levels of physical activity are associated with the best long-term outcomes [79-82]. The mechanism of action for the possible benefit of high levels of physical activity is unclear, but candidates include maintenance of energy balance, prevention of loss of fat-free mass, and improved $\operatorname{mood}[83,84]$.

Future research must determine the optimal method of promoting physical activity in obese adolescents. Several studies have examined ways of promoting physical activity for weight control in adults. These studies have found that lifestyle activity and home-based activity may be especially helpful for weight loss maintenance [85-87]. Special considerations for adolescents include the extent to which parents, peers, and the environment at home, school, and in the community provide support for physical activity, as well as the extent to which these factors promote sedentary activity. Many adolescents have less autonomy for behavior change than adults, so providers may need to be creative with physical activity promotion and instruct parents in providing support for physical activity. Because adolescence is a time of heightened risk for eating disorders, research also should evaluate any risk of excessive exercise that is conferred by treatment.

\section{Internet-Based Intervention}

7.1. Use of Internet-Based Intervention. Recently, the Internet has been studied as a method of delivering lifestyle modification programs. These interventions have the potential to reach large numbers of adolescents, to improve cost-effectiveness, and to facilitate extended contact with the treatment team, which appears beneficial for weight loss maintenance. Many of the features of Internet-based treatment may be especially appealing to adolescents: (1) intervention resources often can be used at anytime, so consistency in scheduling is not necessary, (2) the patient does not need to rely on an adult for transportation to treatment, (3) therapy may be received with a certain amount of anonymity, which can be beneficial for adolescents who experience self-consciousness with regard to weight control, and (4) the Internet provides a means of receiving social support and sharing information that is already very familiar to most adolescents.

\subsection{Long-Term Effectiveness of Internet-Based Intervention in} Adolescents. Despite the intuitive appeal of such an approach with adolescents, few trials have examined the efficacy of an Internet-based lifestyle modification program for teens. The most applicable study, conducted by Williamson et al. [44], compared a 2-year interactive behavioral Internet program (i.e., treatment group) to an Internet health education program (i.e., control). Participants were overweight African American adolescents and their parents. All participants also received four face-to-face counseling sessions. At 6 months, adolescents in the treatment group lost significantly more body fat than those in the control condition. However, the difference between groups was not maintained at 2 years, possibly because website usage decreased substantially during the second year of treatment.

Two other Internet programs that had aims in addition to weight control have been examined in RCTs with adolescents. The first study tested an Internet program designed to promote weight loss and improve body image [45]. Analysis of treatment completers (but not ITT analyses) found that at posttreatment, the intervention group had significantly greater (though modest) improvements in BMI z-scores than the psychoeducational control group. In either type of analysis, the BMI z-score did not significantly differ between groups at 4-months followup. The second study evaluated an Internet program for weight maintenance and reduction of binge eating [46]. The intervention group had significantly greater reductions in BMI z-scores than the control group. Among completers, $27 \%$ of the intervention group and $12 \%$ of the control group had a BMI below the 85 th percentile at followup.

7.3. Conclusions. RCTs that examined weight loss maintenance after Internet-based treatments for adolescents present a mixed picture. These interventions appeared more effective than minimal-contact comparison interventions for some period of time, but it was not clear how well group differences could be sustained. Even when group differences were found, 
the limited effectiveness of such approaches was apparent; for example, Jones et al. [46] found that three-quarters of the intervention group remained overweight or obese at followup.

Research from the adult literature on Internet-delivered interventions also has been mixed with some studies demonstrating that these interventions were as effective for weight loss maintenance as face-to-face intervention $[75,88]$, and some studied demonstrating that Internet interventions were less effective $[61,89]$. Some studies found that adult participants in face-to-face programs were more satisfied with their treatment and attended more sessions than those in Internet programs $[88,89]$. Treatment acceptability must be measured in future research to determine if this is the case with adolescents. The use of telephone-based treatment in adolescents also should be explored. The adult literature on use of telephone contacts for weight maintenance is small but promising [90-92]. However, such programs will only have long-term success if they are implemented in a way that maximizes continued engagement of patients [93]. In summary, effective programs delivered via Internet or telephone should be developed, especially as an option for adolescents who do not have access to face-to-face treatment. Further evaluation of these programs as a method of extending treatment contact also is needed.

\section{Medication}

8.1. Use of Medication. Orlistat is the only medication approved in the U.S. for the induction and maintenance of weight loss in adults and adolescents (age 12-16). Orlistat is a gastric and pancreatic lipase inhibitor that induces weight loss by blocking the absorption of about one-third of the fat contained in a meal [94]. The undigested fat (i.e., oil) is excreted in stool and may be associated with gastrointestinal events that include oily stools, flatulence with discharge, and related complications [94].

Until recently, sibutramine, a combined serotoninnorepinephrine reuptake inhibitor (SNRI) that is associated with increased satiation (i.e., fullness) and a resulting reduction in food intake, was Food and Drug Administration (FDA) approved for adolescents 16 years of age or older [95]. The data on sibutramine use in adolescents indicated that it produced large weight loss (e.g., 8.0\% of weight loss after 1 year of treatment) and significantly greater improvements in waist circumference, HDL cholesterol, triglycerides, and insulin sensitivity compared with placebo [13, 96-98]. However, adolescents taking sibutramine typically experienced small increases in diastolic blood pressure (about $1 \mathrm{~mm} \mathrm{Hg}$ ) and pulse rate (4-5 beats per minute), as compared with placebo. Recently, the SCOUT Trial [99] examined sibutramine's effects for up to 5 years in adults age 55 years or older with known cardiovascular disease (or type 2 diabetes with at least one additional risk factor for cardiac disease). Patients taking sibutramine experienced an increased risk of cardiovascular events, including myocardial infarction and stroke, compared with placebo-treated patients [100, 101]. As a result, the FDA and the European Medicines
Agency recommended withdrawal of the medication from the market, arguing that the benefits of treatment did not outweigh its risks.

8.2. Long-Term Effectiveness of Medication in Adolescents. Orlistat's efficacy in adolescents has been examined in two RCTs longer than 8 months, each of which provided modest lifestyle modification programs in conjunction with medication. In the larger of the two studies, conducted by Chanoine et al. [47], participants who received orlistat experienced a weight gain of $0.5 \mathrm{~kg}$ at the end of 1 year of treatment, compared to a weight gain of $3.1 \mathrm{~kg}$ in participants who received placebo (a significant difference). The smaller study [48], which was not placebo-controlled, found that participants taking orlistat lost of average of $6.3 \mathrm{~kg}$ during 1 year of treatment, whereas those in the control group gained an average of $4.2 \mathrm{~kg}$ (a significant difference). In a metaanalysis conducted by McGovern et al. [9], the combined effect across studies of all duration was a decrease in BMI of $0.7 \mathrm{~kg} / \mathrm{m}^{2}$. The most methodologically sound evidence indicates that the size of the weight loss produced and sustained by orlistat is small. The medication also may be unappealing to adolescents because of its gastrointestinal side effects. No study has conducted a followup to determine the extent to which weight loss is maintained after orlistat is discontinued.

8.3. Conclusions. Orlistat has been evaluated in combination with lifestyle modification in obese adolescents. This medication resulted in a better weight control than lifestyle modification alone after 1 year, but the amount of weight loss produced may be relatively small. Additional research with adolescents is needed to determine if use of orlistat can be extended to promote better weight loss maintenance and to collect longer-term safety data. Two RCTs that examined the long-term effectiveness of orlistat in adults found that patients who received 2 years of orlistat had significantly better weight loss maintenance than those who received placebo [94, 102]. Adolescents enrolled in RCTs of orlistat generally found the gastrointestinal side effects of the medication acceptable, but additional data should be collected outside of an RCT population. More data also should be collected on the ability of adolescents to comply with a low-fat diet when taking orlistat. Finally, it is critical that health care providers who prescribe medication to adolescents also prescribe a lifestyle modification program. The effectiveness of medication is attenuated in the absence of this lifestyle modification [103-105].

\section{Comment}

There is a striking paucity of research on weight loss maintenance in adolescents. Research on weight loss maintenance in adults is much more extensive and should guide future research on adolescents, with the caveat that special developmental factors must be considered when designing and evaluating programs for adolescents. The available research suggests that lifestyle modification has promise, although it 
is not clear that any particular dietary or physical activity component is much more effective than another. Meal replacements are quite effective in adults and deserve further research in adolescents. Extending the length of treatment to teach weight loss maintenance skills is likely to improve longterm outcomes, and delivering treatment via the Internet or telephone is one novel way of doing so. Treatment that combines lifestyle modification with orlistat appears safe but medications that induce and maintain larger weight losses are needed. Far greater resources must be devoted to identifying methods to improve weight management in obese adolescents.

\section{Acknowldgments}

This work was supported by a Health Research Grant from the Pennsylvania Department of Health (no. SAP4100033130). The views presented in this manuscript are those of the authors.

\section{References}

[1] A. A. Hedley, C. L. Ogden, C. L. Johnson, M. D. Carroll, L. R. Curtin, and K. M. Flegal, "Prevalence of overweight and obesity among US children, adolescents, and adults, 19992002," Journal of the American Medical Association, vol. 291, no. 23, pp. 2847-2850, 2004.

[2] R. J. Kuczmarski, C. L. Ogden, L. M. Grummer-Strawn et al., "CDC growth charts: United States," Advance Data from Vital and Health Statistics, vol. 314, no. 1, pp. 1-27, 2000.

[3] M. C. Bellizzi and W. H. Dietz, "Workshop on childhood obesity: summary of the discussion," American Journal of Clinical Nutrition, vol. 70, no. 1, pp. 173S-175S, 1999.

[4] W. H. Dietz and M. C. Bellizzi, "Introduction: the use of body mass index to assess obesity in children," American Journal of Clinical Nutrition, vol. 70, no. 1, pp. 123S-125S, 1999.

[5] S. K. Kumanyika, E. Obarzanek, N. Stettler et al., "Population-based prevention of obesity: the need for comprehensive promotion of healthful eating, physical activity, and energy balance: a scientific statement from American Heart Association Council on Epidemiology and Prevention, Interdisciplinary Committee for prevention (formerly the expert panel on population and prevention science)," Circulation, vol. 118, no. 4, pp. 428-464, 2008.

[6] H. Oude Luttikhuis, L. Baur, H. Jansen et al., "Interventions for treating obesity in children," Cochrane Database of Systematic Reviews, no. 1, p. CD001872, 2009.

[7] S. E. Barlow, "Expert committee recommendations regarding the prevention, assessment, and treatment of child and adolescent overweight and obesity: summary report," Pediatrics, vol. 120, supplement 4, pp. S164-S192, 2007.

[8] A. -M. Glenny, S. O’Meara, A. Melville, T. A. Sheldon, and C. Wilson, "The treatment and prevention of obesity: a systematic review of the literature," International Journal of Obesity, vol. 21, no. 9, pp. 715-737, 1997.

[9] L. McGovern, J. N. Johnson, R. Paulo et al., "Treatment of pediatric obesity: a systematic review and meta-analysis of randomized trials," Journal of Clinical Endocrinology and Metabolism, vol. 93, no. 12, pp. 4600-4605, 2008.

[10] E. P. Whitlock, E. A. O'Connor, S. B. Williams, T. L. Beil, and K. W. Lutz, "Effectiveness of weight management interventions in children: a targeted systematic review for the USPSTF," Pediatrics, vol. 125, no. 2, pp. e396-e418, 2010.

[11] G. P. August, S. Caprio, I. Fennoy et al., "Prevention and treatment of pediatric obesity: an Endocrine Society clinical practice guideline based on expert opinion," Journal of Clinical Endocrinology and Metabolism, vol. 93, no. 12, pp. 4576-4599, 2008.

[12] G. Rao, "Childhood obesity: highlights of AMA Expert Committee recommendations," American Family Physician, vol. 78, no. 1, pp. 56-66, 2008.

[13] R. I. Berkowitz, T. A. Wadden, A. M. Tershakovec, and J. L. Cronquist, "Behavior therapy and sibutramine for the treatment of adolescent obesity:a randomized controlled trial," Journal of the American Medical Association, vol. 289, no. 14, pp. 1805-1812, 2003.

[14] F. X. Pi-Sunyer, "Medical hazards of obesity," Annals of Internal Medicine, vol. 119, no. 7, pp. 655-660, 1993.

[15] Sciences NAo, Implications for Reducing Chronic Disease Risk, National Research Council, Food and Nutrition Board Diet and Health, Washington, DC, USA, 1989.

[16] J. E. Manson, W. C. Willett, M. J. Stampfer et al., "Body weight and mortality among women," The New England Journal of Medicine, vol. 333, no. 11, pp. 677-685, 1995.

[17] L. DiPietro, H. -O. Mossberg, and A. J. Stunkard, "A 40year history of overweight children in Stockholm: life-time overweight, morbidity, and mortality," International Journal of Obesity, vol. 18, no. 9, pp. 585-590, 1994.

[18] A. Must, P. F. Jacques, G. E. Dallal, C. J. Bajema, and W. H. Dietz, "Long-term morbidity and mortality of overweight adolescents-a follow-up of the Harvard Growth Study of 1922 to 1935," The New England Journal of Medicine, vol. 327, no. 19, pp. 1350-1355, 1992.

[19] M. S. Schwartz and A. Chadha, "Type 2 diabetes mellitus in childhood: obesity and insulin resistance," Journal of the American Osteopathic Association, vol. 108, no. 9, pp. 518524, 2008.

[20] E. J. Mayer-Davis, R. A. Bell, D. Dabelea et al., "The many faces of diabetes in American youth: type 1 and type 2 diabetes in five race and ethnic populations: the SEARCH for diabetes in youth study," Diabetes Care, vol. 32, no. 2, pp. S99-S101, 2009.

[21] Diabetes in America, National Diabetes Data Group, Bethesda, Md, USA, 1995.

[22] O. Pinhas-Hamiel, L. M. Dolan, S. R. Daniels, D. Standiford, P. R. Khoury, and P. Zeitler, "Increased incidence of noninsulin-dependent diabetes mellitus among adolescents," Journal of Pediatrics, vol. 128, no. 5 I, pp. 608-615, 1996.

[23] S. M. Camhi, J. Kuo, and D. R. Young, "Identifying adolescent metabolic syndrome using body mass index and waist circumference," Preventing Chronic Disease, vol. 5, no. 4, p. A115, 2008.

[24] W. H. Dietz, "Health consequences of obesity in youth: childhood predictors of adult disease," Pediatrics, vol. 101, no. 3, pp. 518-525, 1998.

[25] S. L. Gortmaker, A. Must, J. M. Perrin, A. M. Sobol, and W. H. Dietz, "Social and economic consequences of overweight in adolescence and young adulthood," The New England Journal of Medicine, vol. 329, no. 14, pp. 1008-1012, 1993.

[26] R. M. Van Dam, W. C. Willett, J. E. Manson, and F. B. Hu, "The relationship between overweight in adolescence and premature death in women," Annals of Internal Medicine, vol. 145, no. 2, pp. 91-97, 2006. 
[27] J. B. Schwimmer, T. M. Burwinkle, and J. W. Varni, "Healthrelated quality of life of severely obese children and adolescents," Journal of the American Medical Association, vol. 289, no. 14, pp. 1813-1819, 2003.

[28] W. C. Knowler, E. Barrett-Connor, S. E. Fowler et al., "Reduction in the incidence of type 2 diabetes with lifestyle intervention or metformin," The New England Journal of Medicine, vol. 346, no. 6, pp. 393-403, 2002.

[29] J. Tuomilehto, J. Lindström, J. G. Eriksson et al., "Prevention of type 2 diabetes mellitus by changes in lifestyle among subjects with impaired glucose tolerance," The New England Journal of Medicine, vol. 344, no. 18, pp. 1343-1350, 2001.

[30] D. J. Goldstein, "Beneficial health effects of modest weight loss," International Journal of Obesity, vol. 16, no. 6, pp. 397415, 1992.

[31] R. R. Wing, R. Koeske, L. H. Epstein, M. P. Nowalk, W. Gooding, and D. Becker, "Long-term effects of modest weight loss in type II diabetic patients," Archives of Internal Medicine, vol. 147, no. 10, pp. 1749-1753, 1987.

[32] G. Blackburn, "Effect of degree of weight loss on health benefits," Obesity Research, vol. 3, supplement 2, pp. 211s216s, 1995.

[33] T. H. Inge, GO. Miyano, J. Bean et al., "Reversal of type 2 diabetes mellitus and improvements in cardiovascular risk factors after surgical weight loss in adolescents," Pediatrics, vol. 123, no. 1, pp. 214-222, 2009.

[34] L. M. Mellin, L. A. Slinkard, and C. E. Irwin, "Adolescent obesity intervention: validation of the SHAPEDOWN program," Journal of the American Dietetic Association, vol. 87, no. 3, pp. 333-338, 1987.

[35] J. X. Jiang, X. L. Xia, T. Greiner, G. L. Lian, and U. Rosenqvist, "A two year family based behaviour treatment for obese children," Archives of Disease in Childhood, vol. 90, no. 12, pp. 1235-1238, 2005.

[36] T. J. Coates, J. D. Killen, and L. A. Slinkard, "Parent participation in a treatment program for overweight adolescents," International Journal of Eating Disorders, vol. 1, no. 3, pp. 3748, 2006.

[37] K. D. Brownell, J. H. Kelman, and A. J. Stunkard, "Treatment of obese children with and without their mothers: changes in weight and blood pressure," Pediatrics, vol. 71, no. 4, pp. 515-523, 1983.

[38] T. A. Wadden, A. J. Stunkard, L. Rich, C. J. Rubin, G. Sweidel, and S. McKinney, "Obesity in black adolescent girls: a controlled clinical trial of treatment by diet, behavior modification, and parental support," Pediatrics, vol. 85, no. 3, pp. 345-352, 1990.

[39] T. J. Coates, R. W. Jeffery, and L. A. Slinkard, "Frequency of contact and monetary reward in weight loss, lipid change, and blood pressure reduction with adolescents," Behavior Therapy, vol. 13, no. 2, pp. 175-185, 1982.

[40] K. Resnicow, R. Taylor, M. Baskin, and F. McCarty, "Results of go girls: a weight control program for overweight AfricanAmerican adolescent females," Obesity Research, vol. 13, no. 10, pp. 1739-1748, 2005.

[41] C. B. Ebbeling, M. M. Leidig, K. B. Sinclair, J. P. Hangen, and D. S. Ludwig, "A reduced-glycemic load diet in the treatment of adolescent obesity," Archives of Pediatrics and Adolescent Medicine, vol. 157, no. 8, pp. 773-779, 2003.

[42] B. Gutin, P. Barbeau, S. Owens et al., "Effects of exercise intensity on cardiovascular fitness, total body composition, and visceral adiposity of obese adolescents," American Journal of Clinical Nutrition, vol. 75, no. 5, pp. 818-826, 2002.
[43] E. Jelalian, R. Mehlenbeck, E. E. Lloyd-Richardson, V. Birmaher, and R. R. Wing, "Adventure therapy' combined with cognitive-behavioral treatment for overweight adolescents," International Journal of Obesity, vol. 30, no. 1, pp. 31-39, 2006.

[44] D. A. Williamson, H. M. Walden, M. A. White et al., "Twoyear internet-based randomized controlled trial for weight loss in African-American girls," Obesity, vol. 14, no. 7, pp. 1231-1243, 2006.

[45] A. C. Doyle, A. Goldschmidt, C. Huang, A. J. Winzelberg, C. B. Taylor, and D. E. Wilfley, "Reduction of overweight and eating disorder symptoms via the internet in adolescents: a randomized controlled trial," Journal of Adolescent Health, vol. 43, no. 2, pp. 172-179, 2008.

[46] M. Jones, K. H. Luce, M. I. Osborne et al., "Randomized, controlled trial of an internet-facilitated intervention for reducing binge eating and overweight in adolescents," Pediatrics, vol. 121, no. 3, pp. 453-462, 2008.

[47] J. P. Chanoine, S. Hampl, C. Jensen, M. Boldrin, and J. Hauptman, "Effect of orlistat on weight and body composition in obese adolescents: a randomized controlled trial," Journal of the American Medical Association, vol. 293, no. 23, pp. 2873-2883, 2005.

[48] B. Ozkan, A. Bereket, S. Turan, and S. Keskin, "Addition of orlistat to conventional treatment in adolescents with severe obesity," European Journal of Pediatrics, vol. 163, no. 12, pp. 738-741, 2004

[49] W. G. Johnson, L. K. Hinkle, R. E. Carr et al., "Dietary and exercise interventions for juvenile obesity: long-term effect of behavioral and public health models," Obesity Research, vol. 5, no. 3, pp. 257-261, 1997.

[50] C. K. Haddock, W. R. Shadish, R. C. Klesges, and R. J. Stein, "Treatments for childhood and adolescent obesity," Annals of Behavioral Medicine, vol. 16, no. 3, pp. 235-244, 1994.

[51] L. H. Epstein, R. A. Paluch, C. C. Gordy, and J. Dorn, "Decreasing sedentary behaviors in treating pediatric obesity," Archives of Pediatrics and Adolescent Medicine, vol. 154, no. 3, pp. 220-226, 2000.

[52] L. H. Epstein, J. N. Roemmich, J. L. Robinson et al., "A randomized trial of the effects of reducing television viewing and computer use on body mass index in young children," Archives of Pediatrics and Adolescent Medicine, vol. 162, no. 3, pp. 239-245, 2008.

[53] L. H. Epstein and R. R. Wing, "Behavioral treatment of childhood obesity," Psychological Bulletin, vol. 101, no. 3, pp. 331-342, 1987.

[54] T. A. Wadden, M. L. Butryn, and C. Wilson, "Lifestyle modification for the management of obesity," Gastroenterology, vol. 132, no. 6, pp. 2226-2238, 2007.

[55] M. L. Dansinger, A. Tatsioni, J. B. Wong, M. Chung, and E. M. Balk, "Meta-analysis: the effect of dietary counseling for weight loss," Annals of Internal Medicine, vol. 147, no. 1, pp. 41-50, 2007.

[56] M. G. Perri and J. A. Corsica, "Improving the maintenance of weight lost in behavioral treatment of obesity," in Handbook of Obesity Treatment, pp. 357-379, 2002.

[57] R. R. Wing, J. L. Bahnson, G. A. Bray et al., "Long-term effects of a lifestyle intervention on weight and cardiovascular risk factors in individuals with type 2 diabetes mellitus: fouryear results of the look AHEAD trial," Archives of Internal Medicine, vol. 170, no. 17, pp. 1566-1575, 2010.

[58] T. A. Wadden and M. L. Butryn, "Behavioral treatment of obesity," Endocrinology and Metabolism Clinics of North America, vol. 32, no. 4, pp. 981-1003, 2003. 
[59] R. Leibbrand and M. M. Fichter, "Maintenance of weight loss after obesity treatment: is continuous support necessary?" Behaviour Research and Therapy, vol. 40, no. 11, pp. 12751289, 2002.

[60] D. Riebe, B. Blissmer, G. Greene et al., "Long-term maintenance of exercise and healthy eating behaviors in overweight adults," Preventive Medicine, vol. 40, no. 6, pp. 769-778, 2005.

[61] L. P. Svetkey, V. J. Stevens, P. J. Brantley et al., "Comparison of strategies for sustaining weight loss: the weight loss maintenance randomized controlled trial," Journal of the American Medical Association, vol. 299, no. 10, pp. 1139 1148, 2008.

[62] C. Apovian, S. Bigornia, D. Cullum-Dugan et al., "Milkbased nutritional supplements in conjunction with lifestyle intervention in overweight adolescents," Infant, Child, \& Adolescent Nutrition, vol. 1, no. 1, pp. 37-44, 2009.

[63] D. G. Schlundt, J. O. Hill, J. Pope-Cordle, D. Arnold, K. L. Virts, and M. Katahn, "Randomized evaluation of a low fat "ad libitum" carbohydrate diet for weight reduction," International Journal of Obesity and Related Metabolic Disorders, vol. 17, pp. 623-629, 1993.

[64] S. Toubro and A. Astrup, "Randomised comparison of diets for maintaining obese subjects' weight after major weight loss: ad lib, low fat, high carbohydrate diet $\mathrm{v}$ fixed energy intake," British Medical Journal, vol. 314, no. 7073, pp. 29-34, 1997.

[65] G. D. Foster, H. R. Wyatt, J. O. Hill et al., "A randomized trial of a low-carbohydrate diet for obesity," The New England Journal of Medicine, vol. 348, no. 21, pp. 2082-2090, 2003.

[66] L. Stern, N. Iqbal, P. Seshadri et al., "The effects of lowcarbohydrate versus conventional weight loss diets in severely obese adults: one-year follow-up of a randomized trial," Annals of Internal Medicine, vol. 140, no. 10, pp. 778-785, 2004.

[67] I. Shai, D. Schwarzfuchs, Y. Henkin et al., "Weight loss with a low-carbohydrate, Mediterranean, or low-fat diet," The New England Journal of Medicine, vol. 359, no. 3, pp. 229-241, 2008.

[68] F. M. Sacks, G. A. Bray, V. J. Carey et al., "The The New England Journal of Medicine: comparison of weightloss diets with different compositions of fat, protein, and carbohydrates," The New England Journal of Medicine, vol. 360, no. 9, pp. 859-873, 2009.

[69] R. W. Jeffery, R. R. Wing, C. Thorson et al., "Strengthening behavioral interventions for weight loss: a randomized trial of food provision and monetary incentives," Journal of Consulting and Clinical Psychology, vol. 61, no. 6, pp. 1038$1045,1993$.

[70] S. B. Heymsfield, C. A.J. Van Mierlo, H. C.M. Van Der Knaap, M. Heo, and H. I. Frier, "Weight management using a meal replacement strategy: meta and pooling analysis from six studies," International Journal of Obesity, vol. 27, no. 5, pp. 537-549, 2003.

[71] H. H. Ditschuneit and M. Flechtner-Mors, "Value of structured meals for weight management: risk factors and longterm weight maintenance," Obesity Research, vol. 9, pp. S284S289, 2001.

[72] T. A. Wadden and R. I. Berkowitz, "Very-low-calorie diets," in Eating Disorders and Obesity, pp. 534-538, 2002.

[73] B. J. Rolls, "Experimental analyses of the effects of variety in a meal on human feeding," American Journal of Clinical Nutrition, vol. 42, no. 5, pp. 932-939, 1985.

[74] B. J. Rolls, "Sensory-specific satiety," Nutrition Reviews, vol. 44, no. 3, pp. 93-101, 1986.
[75] R. R. Wing, D. F. Tate, A. A. Gorin, H. A. Raynor, and J. L. Fava, "A self-regulation program for maintenance of weight loss," The New England Journal of Medicine, vol. 355, no. 15, pp. 1563-1571, 2006.

[76] R. R. Wing, R. W. Jeffery, L. R. Burton, C. Thorson, K. S. Nissinoff, and J. E. Baxter, "Food provision vs structured meal plans in the behavioral treatment of obesity," International Journal of Obesity, vol. 20, no. 1, pp. 56-62, 1996.

[77] M. L. Butryn and T. A. Wadden, "Treatment of overweight in children and adolescents: does dieting increase the risk of eating disorders?" International Journal of Eating Disorders, vol. 37, no. 4, pp. 285-293, 2005.

[78] S. N. Blair and E. A. Leermakers, "Exercise and weight management," in Handbook of Obesity Treatment, pp. 283300, Guilford Press, New York, NY, USA, 2002.

[79] J. M. Jakicic, B. H. Marcus, K. I. Gallagher, M. Napolitano, and W. Lang, "Effect of exercise duration and intensity on weight loss in overweight, sedentary women: a randomized trial," Journal of the American Medical Association, vol. 290, no. 10, pp. 1323-1330, 2003.

[80] V. A. Catenacci, L. G. Ogden, J. Stuht et al., "Physical activity patterns in the national weight control registry," Obesity, vol. 16 , no. 1, pp. 153-161, 2008.

[81] D. F. Tate, R. W. Jeffery, N. E. Sherwood, and R. R. Wing, "Long-term weight losses associated with prescription of higher physical activity goals. Are higher levels of physical activity protective against weight regain?" American Journal of Clinical Nutrition, vol. 85, no. 4, pp. 954-959, 2007.

[82] R. W. Jeffery, R. R. Wing, N. E. Sherwood, and D. F. Tate, "Physical activity and weight loss: does prescribing higher physical activity goals improve outcome?" American Journal of Clinical Nutrition, vol. 78, no. 4, pp. 684-689, 2003.

[83] D. L. Ballor and E. T. Poehlman, "Exercise-training enhances fat-free mass preservation during diet-induced weight loss: a meta-analytical finding," International Journal of Obesity, vol. 18, no. 1, pp. 35-40, 1994.

[84] T. A. Wadden, R. A. Vogt, R. E. Andersen et al., "Exercise in the treatment of obesity: effects of four interventions on body composition, resting energy expenditure, appetite, and mood," Journal of Consulting and Clinical Psychology, vol. 65, no. 2, pp. 269-277, 1997.

[85] L. H. Epstein, R. R. Wing, R. Koeske, and A. Valoski, "A comparison of lifestyle exercise, aerobic exercise, and calisthenics on weight loss in obese children," Behavior Therapy, vol. 16, no. 4, pp. 345-356, 1985.

[86] R. E. Andersen, T. A. Wadden, S. J. Bartlett, B. Zemel, T. J. Verde, and S. C. Franckowiak, "Effects of lifestyle activity vs structured aerobic exercise in obese women: a randomized trial," Journal of the American Medical Association, vol. 281, no. 4, pp. 335-340, 1999.

[87] M. G. Perri, A. D. Martin, E. A. Leermakers, S. F. Sears, and M. Notelovitz, "Effects of group- versus home-based exercise in the treatment of obesity," Journal of Consulting and Clinical Psychology, vol. 65, no. 2, pp. 278-285, 1997.

[88] J. Harvey-Berino, S. Pintauro, P. Buzzell, and E. C. Gold, "Effect of internet support on the long-term maintenance of weight loss," Obesity Research, vol. 12, no. 2, pp. 320-329, 2004.

[89] J. Harvey-Berino, S. Pintauro, P. Buzzell et al., "Does using the Internet facilitate the maintenance of weight loss?" International Journal of Obesity, vol. 26, no. 9, pp. 1254-1260, 2002.

[90] M. G. Perri, R. M. Shapiro, and W. W. Ludwig, "Maintenance strategies for the treatment of obesity: an evaluation of 
relapse prevention training and posttreatment contact by mail and telephone," Journal of Consulting and Clinical Psychology, vol. 52, no. 3, pp. 404-413, 1984.

[91] R. R. Wing, R. W. Jeffery, W. L. Hellerstedt, and L. R. Burton, "Effect of frequent phone contacts and optional food provision on maintenance of weight loss," Annals of Behavioral Medicine, vol. 18, no. 3, pp. 172-176, 1996.

[92] M. G. Perri, M. C. Limacher, P. E. Durning et al., "Extendedcare programs for weight management in rural communities: the Treatment of Obesity in Underserved Rural Settings (TOURS) randomized trial," Archives of Internal Medicine, vol. 168, no. 21, pp. 2347-2354, 2008.

[93] N. E. Sherwood, R. W. Jeffery, N. P. Pronk et al., "Mail and phone interventions for weight loss in a managed-care setting: weigh-to-be 2-year outcomes," International Journal of Obesity, vol. 30, no. 10, pp. 1565-1573, 2006.

[94] L. Sjöström, A. Rissanen, T. Andersen et al., "Randomised placebo-controlled trial of orlistat for weight loss and prevention of weight regain in obese patients," The Lancet, vol. 352, no. 9123, pp. 167-172, 1998.

[95] W. P. T. James, A. Astrup, N. Finer et al., "Effect of sibutramine on weight maintenance after weight loss: a randomised trial," The Lancet, vol. 356, pp. 2119-2125, 2000.

[96] R. I. Berkowitz, K. Fujioka, S. R. Daniels et al., "Effects of sibutramine treatment in obese adolescents: a randomized trial," Annals of Internal Medicine, vol. 145, no. 2, pp. 81-90, 2006.

[97] A. Godoy-Matos, L. Carraro, A. Vieira et al., "Treatment of obese adolescents with sibutramine: a randomized, doubleblind, controlled study," Journal of Clinical Endocrinology and Metabolism, vol. 90, no. 3, pp. 1460-1465, 2005.

[98] L. M. García-Morales, A. Berber, C. C. Macias-Lara, C. Lucio-Ortiz, B. E. Del-Rio-Navarro, and L. M. DorantesAlvárez, "Use of sibutramine in obese mexican adolescents: a 6-month, randomized, double-blind, placebo-controlled, parallel-group trial," Clinical Therapeutics, vol. 28, no. 5, pp. 770-782, 2006.

[99] W. P.T. James, I. D. Caterson, W. Coutinho et al., "Effect of sibutramine on cardiovascular outcomes in overweight and obese subjects," The New England Journal of Medicine, vol. 363, no. 10, pp. 905-917, 2010.

[100] B. M. Kuehn, "Sibutramine Warning," Journal of the American Medical Association, vol. 303, no. 4, p. 322-a, 2010.

[101] G. Williams, "Withdrawal of sibutramine in Europe," BMJ, vol. 340, no. 7743, p. c824, 2010.

[102] M. H. Davidson, J. Hauptman, M. DiGirolamo et al., "Weight control and risk factor reduction in obese subjects treated for 2 years with orlistat: a randomized controlled trial," Journal of the American Medical Association, vol. 281, no. 3, pp. 235242, 1999.

[103] T. A. Wadden, R. I. Berkowitz, L. G. Womble et al., "Randomized trial of lifestyle modification and pharmacotherapy for obesity," The New England Journal of Medicine, vol. 353, no. 20, pp. 2111-2120, 2005.

[104] S. Phelan and T. A. Wadden, "Combining behavioral and pharmacological treatments for obesity," Obesity research, vol. 10, no. 6, pp. 560-574, 2002.

[105] T. A. Wadden, R. I. Berkowitz, D. B. Sarwer, R. PrusWisniewski, and C. Steinberg, "Benefits of lifestyle modification in the pharmacologic treatment of obesity: a randomized trial," Archives of Internal Medicine, vol. 161, no. 2, pp. 218-227, 2001. 


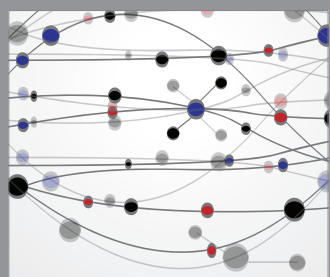

The Scientific World Journal
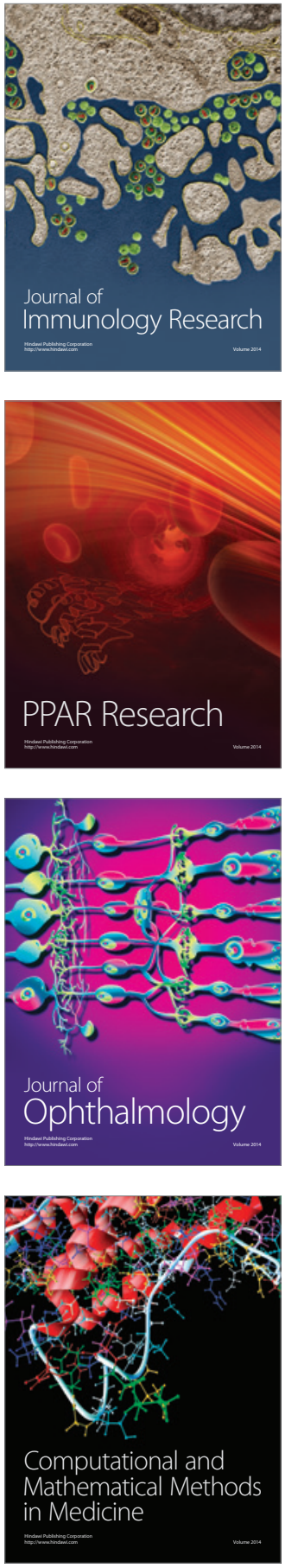

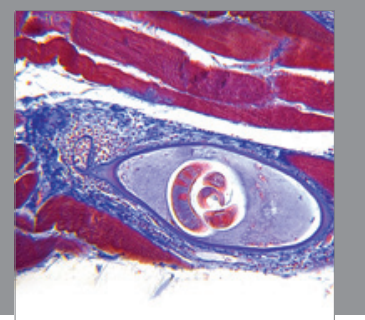

Gastroenterology

Research and Practice
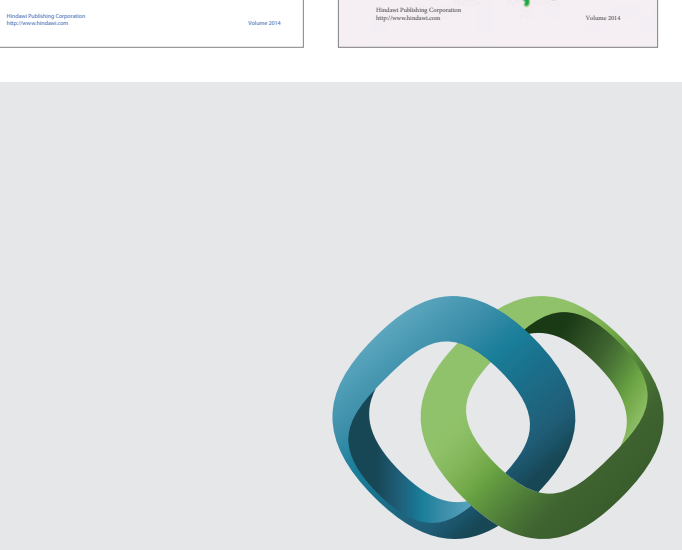

\section{Hindawi}

Submit your manuscripts at

http://www.hindawi.com
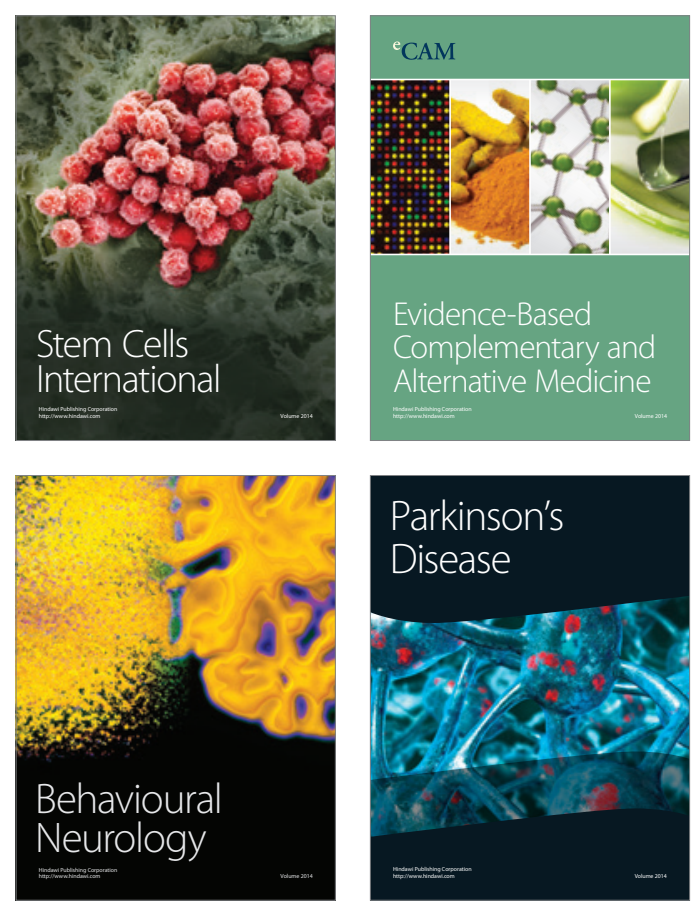

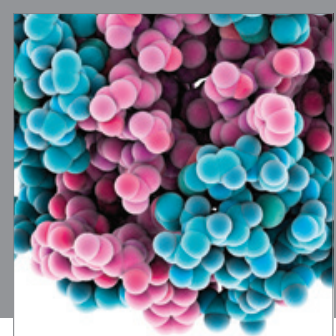

Journal of
Diabetes Research

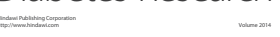

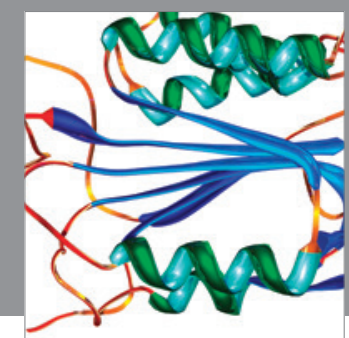

Disease Markers
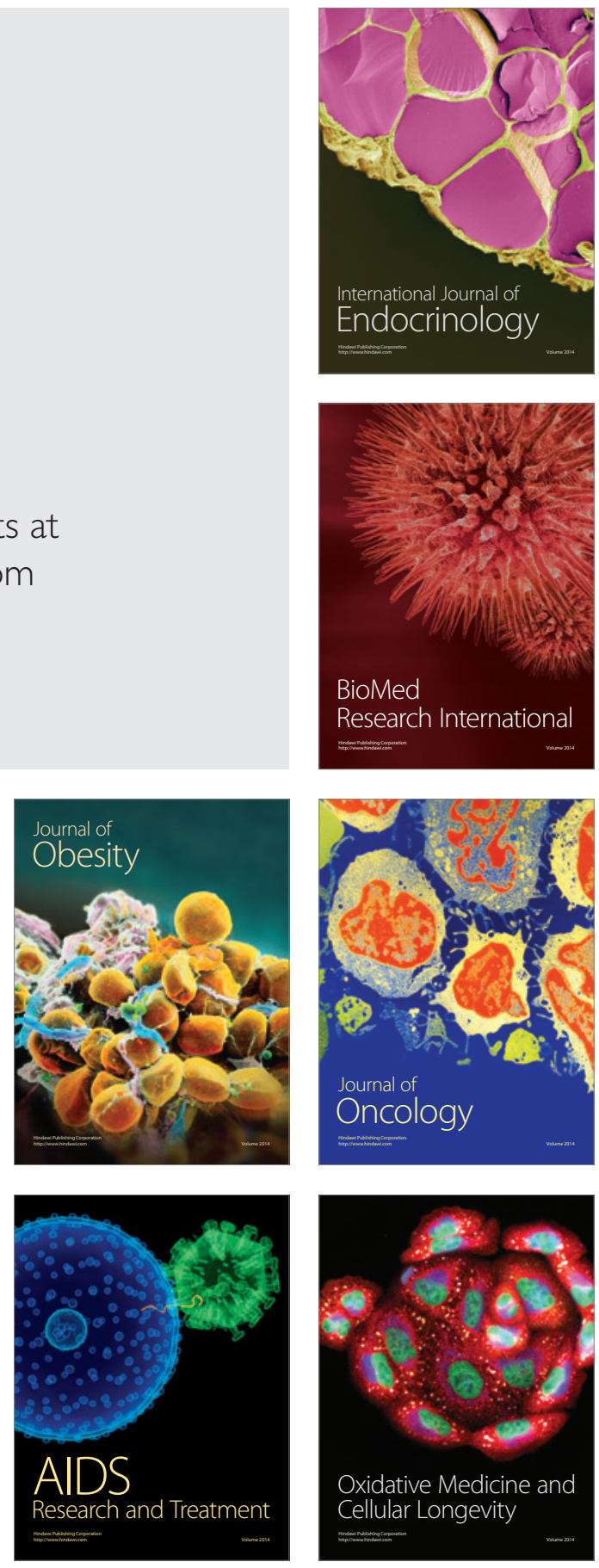